\title{
Presentations and complications of diabetes patients presenting to diabetic clinic of Eastern Nepal
}

Nabin Kumar Singh, ${ }^{1}$ Niraj Kumar Shah, ${ }^{2}$ Amit Bhandari, ${ }^{3}$ Subhash Pandey, ${ }^{4}$ Sanjib Kumar Sharma ${ }^{5}$

${ }^{1-5}$ Department of Internal Medicine,B.P.Koirala Institute of Health Sciences, Dharan, Nepal

\section{ABSTRACT}

\section{Objective}

Diabetes mellitus leads to damage, dysfunction and failure of various organs especially eyes, kidneys, nerves and heart. The latency of occurence of hyperglycemia and diagnosis may be of long duration. This study was aimed to find out the mode of presetation of diabetes mellitus in diabetic patients attending out patients clinic of B P Koirala Institute of Health Sciences. Associated complications and comorbid condition present at the time of presenation were also studied.

\section{Methods}

The diabetic patients attending the Diabetic Out Patient Clinic of B P Koirala Institute of Health Sciences during June 2006 to June 2007 were included in this study.The patients details were collected from the predefined Proforma for diabetes patient from the database. This included demographic data, biochemical parameters and diabetic complications. For the purpose of study a total of 775 patients were randomly selected.The Data collected were entered and analysed using excel and SPSS(version 11.5)

\section{Results}

Out of 775 cases 436 (56.3\%) were male and 339(43.7\%) were female. Majority of patients 81.55\% $(n=632)$ had osmotic sympmtoms or symptoms related to complication of diabetes at the time of presentation to the clinic. Asymptomatic patient constituted $18.45 \%(n=143)$. The most common presenting complaints were polyuria (44.58\%), followed by polydypsia (39.62\%) and polyphagia (24.88\%). About $54.97 \%(n=426)$ had symptoms of complications related to diabetes. Among them most common complication was neurological (39.67\%), followed by renal (10.8\%) metabolic (4.93\%), cardiac(4.46\%), autonomic neuropathy (4.93\%) and peripheral vascular disease $(3.99 \%)$.

\section{Conclusion}

Majority of the patients presenting in our OPD had osmotic symptoms or symptoms related to complication of diabetes. Access to diabetes care and lack of awareness of the disease and its complication might had contributed to this. Community awareness, program for early detection and managemnet may help proper diabetes care and prevention of complications. 
Journal of College of Medical Sciences-Nepal, 2013, Vol-9, No-3,

\section{INTRODUCTION}

Diabetes mellitus(DM) is a group of metabolic syndrome characterized by hyperglycemia resulting from defects in insulin secretion, insulin action or both. It is associated with long term damage, dysfunction and failure of various organs especially eyes, kidneys, nerves and heart. ${ }^{1}$ It affects almost $6 \%$ of the world's population \& prevalence of this chronic disease is increasing. ${ }^{2}$ According to WHO, 180 million people worldwide had diabetes in 2006 and this number is likely to double by $2030 .{ }^{3}$ As a result of changing life style and aging, the prevalence of DM is rapidly increasing around the world. ${ }^{4}$ Nepal is also seing the increasing prevalence of diabetes similar to neighbouring countries in South asia. ${ }^{13}$ However lack of awareness about the disease, its consequences and lack of quality care in diabetes lead to delayed presentation to health care giver that might be associated with more number of complication and comorbid condition of the disease. Therefore, we undertook this study to find out the mode of presentation of diabetes mellitus in diabetetic patients attending out patients clinic (RDPC OPD) of BPKIHS.Associated complications and comorbid condition present at the time of presenation were studied.

\section{METHODS}

The diabetic patients attending the RDPC OPD of BPKIHS during June 2006 to June 2007 were included in this study.The patients details were collected from the predefined Proforma for diabetes patient from the database. This included demographic data(name, age, sex, cast, occupation, address) biochemical parameters (blood sugar random, post parandial, fasting; glycated $\mathrm{Hb}$; urea; creatinine; lipid profile; electrolytes) and diabetic complications.Neurological complications was defined by presence of paraesthesia, numbness, foot drop, wrist drop, mono neuropathy, radiculopathy. Diabetic ketoacidosis, hypoglycemia, hyperosmolar coma was defined as metabolic complications. Cardiac complications was diagonsed by presence of angina, acute myocardial infarction, left ventricular failure, and congestive heart failure. Intermittent claudication, non'healing ulcer and gangrene fulfilled the definition for peripheral vascular complication. Renal complication was defined by oliguria, raised serum creatinine and proteiuria. Autonomic neuropathy was diagnosed by standard bedside autonomic function test.

During this period, the total number of patients attending the diabetetic out patients clinic (RDPC OPD) and medicine OPD of BPKIHS were 1346 and 22,228 respctively. So, the point prevalence of diabetes was $6.06 \%$. For this study a total of 775 patients were randomly selected according to WHO recommended software (EPI Info 2000) to determine the sample size. The Data collected were entered and analysed by Microsoft office excel and statistical package for the social sciences (SPSS Version 11.5).The tests used were Pearson`s Chi-square test.

\section{RESULTS}

Out of 775 cases $436(56.3 \%)$ were male and $339(43.7 \%)$ were female. The mean age was $52.62 \pm 12.5$ years (range: 16 yrs to 90 yrs). Majority $(55.48 \%)$ of the patients were between $40-60$ years of age. Type 2 Diabetes mellitus (T2DM) constituted 763 (98.5\% ) while 12 (1.5\%) were Type-1 Diabetes mellitus. Positive family history of diabetes was present in $38 \%$ in T2DM. 
Nabin Kumar Singh. et al. presentations and complications......

Majority patients (56.77\%) had normal BMI (18.5-

When BMI of e" $23 \mathrm{Kg} / \mathrm{m}^{2}$ is considered for determining 24.9) while $35.1 \%(n=272)$ of patients had BMI above over-weight as recommended for Asian (WHO, 2002) normal and $8.13 \%$ had below normal BMI as per $60.12 \%$ had BMI above normal (e"23kg/m²).

WHO criteria. Table 1 shows the distribution of BMI.

Table 1: Distribution of BMI

\begin{tabular}{|c|c|c|c|c|c|c|}
\hline \multirow[t]{2}{*}{ Age group } & \multirow[b]{2}{*}{$<18.5$} & \multicolumn{3}{|c|}{$\operatorname{BMI}\left(\mathbf{k g} / \mathbf{m}^{2}\right)$} & \multirow[t]{2}{*}{ Total } & \multirow[t]{2}{*}{ P Value } \\
\hline & & $18.5-24.9$ & 25-29.9 & $e^{\prime 30}$ & & \\
\hline$<40$ & 17 & 59 & 25 & 5 & 106 & 0.001 \\
\hline $40-50$ & $' 14$ & 120 & 64 & 5 & 203 & \\
\hline $50-60$ & 11 & 124 & 81 & 11 & 227 & \\
\hline $60-70$ & 12 & 86 & 45 & 8 & 151 & \\
\hline \multirow[t]{3}{*}{ e" 70} & 9 & 51 & 18 & 10 & 88 & \\
\hline & 63 & 440 & 266 & 39 & 775 & \\
\hline & $(8.13 \%)$ & $(56.77 \%)$ & $(30.06 \%)$ & $(5.03 \%)$ & & \\
\hline
\end{tabular}

Majority of patients $81.55 \%(n=632)$ had osmotic sympmtoms or symptoms related to complication of diabetes at the time of presentation to the clinic. Asymptomatic patient constituted $18.45 \%(n=143)$. Among symptomatic patients the most common presenting complaints were polyuria $(44.58 \%)$, followed by polydypsia (39.62\%) and polyphagia $(24.88 \%)$.

About $54.97 \%(n=426)$ had symptoms and/or complications related to diabetes.

The distribution of the complication and presenting symptoms are shown in table 2. Most common presentation was due to osmotic smptoms.

Table 2: Symptoms and complication at the time of presentation to the clinic.

$\begin{array}{lcc}\text { Symptoms/complication } & \text { No. of Patients } & \text { Percentage } \\ \text { Constitutional } & 339 & 79.58 \\ \text { Neurological } & 169 & 39.67 \\ \text { Renal } & 46 & 10.8 \\ \text { Metabolic } & 21 & 4.93 \\ \text { Autonomic neuropathy } & 21 & 4.93 \\ \text { Cardiac } & 19 & 4.46 \\ \text { Peripheral vascular } & 17 & 3.99\end{array}$


Journal of College of Medical Sciences-Nepal, 2013, Vol-9, No-3,

The development of metabolic complication (Pd"0.0001) was strongly associated with duration of diabetes. It was observed that renal $(\mathrm{p}=0.027)$, neurological $(p=0.149)$, peripheral vascular $(p=0.562)$ and cardiac $(\mathrm{p}=0.946)$ complication were not related to duration of diagnosed diabetes.

\section{DISCUSSION}

Worldwide prevalence and incidence of diabetes is increasing. Type 2 diabetes mellitus may remain asymptomatic for varying duration before diagnosis and may present with complications of the disease. In this scenario it is challenging for clinicain to diagnose the disease at its initial stage, in absence of routine health check up program in the country. The occurence of the Type 2 diabetes mellitus progressively increases with age. Present study shows diabetes mellitus to be the most common in the age group of 50-60 years in the population presenting to the hospital with complications or symptoms. As the complications of diabetes starts after 10 to 15 years of the disease onset, it suggest that the occurence of disease may be earlier in our populaion then the Western counterpart. Similar observations were also made in the study conducted in BPKIHS ${ }^{4}$ and NMCTH, Birgunj, ${ }^{13}$ but higher than that observed in Saudi Arabian population. ${ }^{14}$

Our study shows relatively high rate of Type 2 diabetes mellitus in male (56.3\%) compared to female (43.7\%), which was similar to results shown in studies conducted in western Nepal, ${ }^{15}$ but a study conducted in europe showed an increased prevalence in females. ${ }^{16}$ However, this difference may be related to the health seeking behabiour of our society.

There are several studies conducted worldwide to show association of genetic factors with diabetes mellitus ${ }^{5-8}$ (an extremely heterogenous disorder) and this is refelcted in the family history of Type 2 diabetes mellitus. We found $38.19 \%$ of the patients suffering from diabetes mellitus had a positive family history. The positive family history was higher than that reported from neighbouring country in Chandigarh, India study. ${ }^{21}$

Obesity is an independent risk factor for Type 2 diabetes mellitus. ${ }^{17}$ Increase in the prevalence of Type 2 diabetes mellitus upto 28 times was reported in obese than non-obese individual. ${ }^{18}$ Interestingly, an increase in BMI even at relatively low levels in previously normal weight individual greatly increases the risk of diabetes. ${ }^{19}$ Various researches have done work worldwide to show unique relation between high BMI and risk of development of DM. ${ }^{10,11}$ When BMI was adjusted for the WHO-Asian indicators of overweght and obesity (e"23 kg/m² as overweight), $66 \%$ males and $55 \%$ females were either overweight or obese. Similar findings were reported from a study done in Western Nepal (64\% male \& $72.4 \%$ female).$^{20}$ The modernization, industrialization and sedentery lifestyle have been implicated as the major risk factor in the development of Type 2 diabetes mellitus. Type 2 diabetes mellitus is prevantable by adopting healthy lifestyle is illustrated by Finland study. ${ }^{9}$ This kind of healthy lifestyle implimentation should be promoted in Nepal also as there is rapid industrialization, urbanization, availability of cheap energy dense foods in the market forecasting future rise of obesity and obesity related diseases including Type 2 diabetes mellitus.

Diabetes mellitus has always been known with the disease of 3P's - polyuria, polyphagia and polydypsia. In our study about $50.63 \%$ of the symptomatic patients presented with these symptoms, $44.58 \%$ patients presented with polyuria, $39.62 \%$ with polydypsia and $24.88 \%$ with polyphagia, the results were found higher 
Nabin Kumar Singh. et al. presentations and complications..

than the study done in Chandigarh that reported polydypsia and polyuria $25.7 \%$ and $31.1 \%$ respectively. ${ }^{21}$ The other common presenting symptoms were neurological symptoms ( $8.54 \%)$, weight loss $(4.59 \%)$, diminished vision $(3.01 \%)$, swelling leg (2.68\%) and abdominal pain/discomfort (2.05\%).

The most common complication in our study in terms of neurological, renal and metabolic complications were comparable to study done in Chandigarh, ${ }^{21}$ in which peripheral neurpathy was the commonest complication(45.9\%). Singh NP et al reported that peripheral neuropathy was present in $52 \%$ of their cohort at the time of presentation. ${ }^{23}$ Similar study done by C.cardoso, G.Salles in Brazil shows lower result of neuropathy $(15.5 \%)$ but higher result of nephropathy(19.1\%).

Hypertension is common co-morbid condition in population with Type 2 diabetes mellitus. Among the comorbidites, hypertension was found in 280 patients (36.13\%), which is less than as compared to study by S Puria $(41.9 \%) .{ }^{21}$

\section{CONCLUSION}

It is essential to understand the burden of diabetes mellitus in daily functioning and in the society. Majority of the patients presenting in our OPD had osmotic symptoms or symptoms related to complication of diabetes. Access to diabetes care and lack of awareness of the disease and its complication might had contributed to this. Community awareness program for early detection and management may help in preventing complications related to Type 2 diabetes mellitus.

\section{REFERENCES}

1 Adeghate E,Schettner P,Dunne.An update of the etiology \& epidemiology of Diabetes Mellitus .Ann new york Acad Sci;1084:1-29.

2 Adeghate E,Schettner P,Dunne.An update of the etiology \& epidemiology of Diabetes Mellitus .Ann new york Acad Sci;1084:1-29.

3 WHO. Diabetes facts 2006: Fact sheet 312.

4 Mehta RS, Karki P, Sharma SK. Risk factors, associated health problems, reasons for admission and knowledge profile of diabetes patients admitted in BPKIHS.

5 John E. Gerich. The Genetic Basis of Type 2 Diabetes Mellitus. Endocrine Reviews 19 (4): 491-503.

6 Paulsen EP, Richenderfer L, Ginsberg-Fellner F. Plasma glucose, free fatty acids and immunoreactive insulin in sixty-six obese children: studies in reference to a family history of diabetes mellitus. Diabetes 1968 ;17:261269.

7 Lemieux S, Despres J, Nadeau A, Prud'homme D, Trembloy A, Bouchard C. Heterogenous glycemic and insulinemic responses to oral glucose in nondiabetic men: interactions between duration of obesity, body fat distribution and family history of diabetes mellitus. Diabetologia1992; 35:653-659.

8 Migdalis I, Zachariadis D, Kalogeropoulou K, Nounopoulos C, Bouloukos A, Samartzis M. Metabolic abnormalities in offspring of NIDDM patients with a family history of diabetes mellitus. Diabet Med 1996;13:434-440. 
Journal of College of Medical Sciences-Nepal, 2013, Vol-9, No-3,

9 Tuomilehto J, Lindstrom J, Eriksson JG, Valle TTet al. Prevention of Type 2 Diabetes Mellitus by Changes in Lifestyle among Subjects with Impaired Glucose Tolerance. NEJM. 2001;344:1343- 1350.

10 Schienkiewitz A, Schulze MB, Hoffmann K, Kroke A, Boeing H. Body mass index history and risk of type 2 diabetes. Am J Clin Nutr. 2006 Aug;84(2):427-33.

11 J M Chan, E B Rimm, G A Colditz, M J Stampfer, W C Willett. Obesity, fat distribution, and weight gain as risk factors for clinical diabetes in men. Diabetes Care September 1994 17:961-969.

12 Anthonia O Ogbera, Jacob Awobusuyi, Chioma Unachukwu, Olufemi Fasanmade. Clinical features, predictive factors and outcome of hyperglycaemic emergencies in a developing country. BMC Endocrine Disorders 2009, 9:9.

13 M. Adak, S. Nazri. Risk factors assessment for Type-II Diabetes Mellitus

14 Journal of Institute of Medicine, December, 2008; 30:3 23-30

15 Saleh M. Al Osaimi, Khalid S. AL-Gelban. Diabetes Mellitus- Prevalence and associated cardiovascular risk factors in a Saudi sub-urban community. Biomedical Research 2007; 18 (3): 147-153

16 Dinesh K Upadhyay, Subish Palaian, P. Ravi Shankar, Pranaya Mishra. Knowledge, Attitude and Practice about Diabetes among Diabetes Patients in Western Nepal.

17 Rawal Med J 2008;33:8-11
18 Fleming DM, Schellevis FG, Casteren VV. The prevalence of known diabetes in eight European countries. European Journal fo Health 2004:14:1

19 Mokdad AH, Bowman BA, Ford ES, Vinicor F, Marks JS, Koplan JP. The continuing epidemics of obesity and diabetes in the united State. JAMA 2001; 286:1295-2000.

20. Colditz G.,Willett WC, Stampfer MT, Manson JE, Hennekens CH, Arky-RA et al. Weight as risk factor for clinical diabetes in women. Am J Epidemiol 1990;231: 501-513.

21 International Diabetes Federation and International Association for the study of obesity. Diabetes and obesity. Brussels: International Diabetes Federation 2004;25.

22 Shah A, Parthasarathi D, Sarkar D, Saha CG. A comparative study of body mass index (BMI) in diabetic and non- diabetic individuals in Nepalese population. Kathmandu University Medical Journal (2006), Vol. 4, No. 1, Issue $13,4-10$

23 S Puria, M Kalia, C Mangat, N Goel, Abhimanyu, H Swami. Profile of Diabetes mellitus in elderly. The Internet Journal of Geriatrics \& Gerontology 2008 Vol. 4, No. 1.

24 World Health Organisation. Obesity: Preventing and managing the global epidemic. Report of WHO consultation. WHO Tech Rep Ser 2000; 894: 1-253.

25 Singh N P, Pugazhendhi, Das A K et al. Clinical and Laboratory Profile of Diabetes in Elderly. J Indian Med Assoc1999; 97(4):124-8 